\title{
Coal liquefaction using a tetralin-glycerol co-solvent system: effect of temperature and reaction time on conversion and product yield
}

\author{
S. N. Ali ${ }^{1,2}$, K. Ismail ${ }^{1}$, M. A. M. Ishak ${ }^{2} \&$ A. H. Jawad ${ }^{2}$ \\ ${ }^{I}$ Faculty of Applied Sciences, \\ Universiti Teknologi MARA Malaysia, Malaysia \\ ${ }^{2}$ Faculty of Applied Sciences, \\ Universiti Teknologi MARA Perlis, Malaysia
}

\begin{abstract}
Common solvent used in coal liquefaction, namely tetralin, involves very high costs and thus is less likely to be used. A previous study of Mukah Balingian coal liquefaction showed that tetralin-glycerol solvent system with ratio of $70: 30(\mathrm{v} / \mathrm{v})$ provides the highest coal conversion. In this study, the liquefaction process was carried out using this solvent system. The study aimed to determine the effect of liquefaction temperature and reaction time on coal conversion and percentage of product yield. The experimental work was conducted in a $300 \mathrm{ml}$ batchwise reactor system at a temperature of $380-400^{\circ} \mathrm{C}$ with isothermal reaction times ranging from 15 to $45 \mathrm{~min}$. The reaction pressure was about $4 \mathrm{MPa} \mathrm{N} \mathrm{N}_{2}$, and the solvent-to-coal weight ratio was 10:1. Coal liquefaction conversion to tetrahydrofuran soluble products and percent of product yields were determined and the results were tabulated. Based on the results obtained, conversion of coal increases as the temperature and reaction time being increased with the highest value of $78.55 \%$ conversion obtained at $400^{\circ} \mathrm{C}$ and $45 \mathrm{~min}$ reaction time. Increasing temperature also has a significant effect on the percentage of product yield with a higher molecular weight product being produced. Being a temperature sensitive solvent system, increasing reaction time poses different effects on the percentage of product yield for different temperatures used.

Keywords: coal, coal liquefaction, solvent, conversion.
\end{abstract}




\section{Introduction}

Coal is a hydrocarbon like petroleum that exist in solid form because of its greater molecular weight and lower $\mathrm{H} / \mathrm{C}$ ratio. It is categorised into different rank from low rank to high rank namely lignite, sub-bituminous, bituminous and anthracite [1]. The low rank coal such as lignite has low carbon content, high oxygen content with less heating value with comparison to higher rank coals such as bituminous and anthracite. However, low rank coals have a plolymeric-lignin based structure which makes them more preferable to be utilized for liquefaction [2].

Coal liquefaction is a process of extracting liquid fuel from coal at high temperature and high pressure with the aid of hydrogen donor solvent. A hydrogen donor solvent is favoured for this process, as thermal decomposition of coal producing free radicals which needs to be stabilized. By using appropriate hydrogen donor solvent, these radicals can be stabilized by abstracting hydrogen from the solvent and can further inhibits recombination within radicals [3]. Tetralin, a hydrogen donor solvent practically used to liquefy coal due to its excellent hydrogen donor ability [4], however introducing high cost to the process. Researchers have studied alternative solvents such as toluene, ethanol as well as toluene-ethanol, toluene-tetralin, ethanol-tetralin solvent mixtures [5], wash-oil from coal tar and cycle oil from coal liquefaction [6] in order to seek potential solvent to replace the expensive tetralin.

Apart from solvent, temperature is another factor that affects coal liquefaction process. As coal contains complex chemical structure, an elevated temperature is necessary to aid cracking of coal molecules by thermally rupturing carbon-carbon linkages within coal macromolecular structure [7]. On one hand, high temperature able to break more bonds within coal matrix, thus promotes higher conversion and with usage of an excellent hydrogen donor solvent, more lower molecular weight compound can be obtained. Too high temperature on the other hand favours undesirable coking reactions, such as repolymerization and recombination within radicals, thus increasing solid residue content $[7,8]$. This implies how temperature can also affects free radical formation and the subsequent free radical reactions. Therefore, using a suitable reaction temperature is a vital key in obtaining high conversion and oil + gas yield.

Reaction time is also a parameter often being studied in coal liquefaction process. Usual reaction time used are from 0 minute up to few hours. Generally, increasing reaction time causing a decrease in pre-asphaltene content and increasing oil with asphaltene yield. Prolonged reaction time however has no significant effect on conversion and promotes gas formation thus lowering oil yield [8-10].

Previous study on liquefaction of Mukah Balingian low rank coal has utilized tetralin [8] as well as mixed tetralin-supercritical water [10] as liquefaction medium. The results showed that a high coal conversion and oil+gas yield were achieved using the mixed solvent, though the yield was slightly lower than that of tetralin. Another study on liquefaction of this coal using alternative solvent which is tetralin-glycerol has been performed and the suitable tetralin-glycerol ratio of $70: 30(\% \mathrm{v} / \mathrm{v})$ has been obtained [11]. Following this earlier work, extended work 
need to be carried out to further understand the characteristics of this co-solvent system. This present work examines the effect of different temperature and reaction time used in Mukah Balingian coal liquefaction process using tetralin-glycerol co-solvent system on coal conversion and products yield.

\section{Methodology}

\subsection{Coal sample analyses}

Low-rank coal used in this study was Mukah Balingian (MB) Malaysian coal. The coal was pulverised to less than $212 \mu \mathrm{m}$ and dried in a vacuum oven at $100^{\circ} \mathrm{C}$ overnight to remove inherent moisture. Table 1 shows the characteristics of $\mathrm{MB}$ coal.

Table 1: Characteristics of MB coal sample.

\begin{tabular}{lclc}
\hline Ultimate analysis $(\mathrm{wt} \% \mathrm{db})$ & \multicolumn{2}{l}{ Proximate analysis $(\mathrm{wt} \% \mathrm{db})$} \\
\hline Carbon & 60.8 & Volatile matter & 42.72 \\
Hydrogen & 4.9 & Fixed carbon & 48.77 \\
Nitrogen & 1.6 & Ash content & 4.02 \\
Sulphur & 0.2 & Moisture & 3.08 \\
Oxygen* & 32.4 & Fuel ratio & 1.14 \\
H/C ratio & 0.95 & Calorific value & $24.6 \mathrm{MJ} / \mathrm{kg}$ \\
\end{tabular}

*By difference; ${ }^{\#}$ fixed carbon/volatile matter.

\subsection{Liquefaction experiment and product separation}

The liquefaction experiments were carried out in a $300 \mathrm{ml}$ batchwise reactor system. In each run, $10 \mathrm{~g}$ of dried coal with $100 \mathrm{~mL}$ of tetralin-glycerol co-solvent system in 70:30 (v/v) were charged in the vessel with steel ball added. Figure 1 shows schematic diagram of reactor system used in this study.

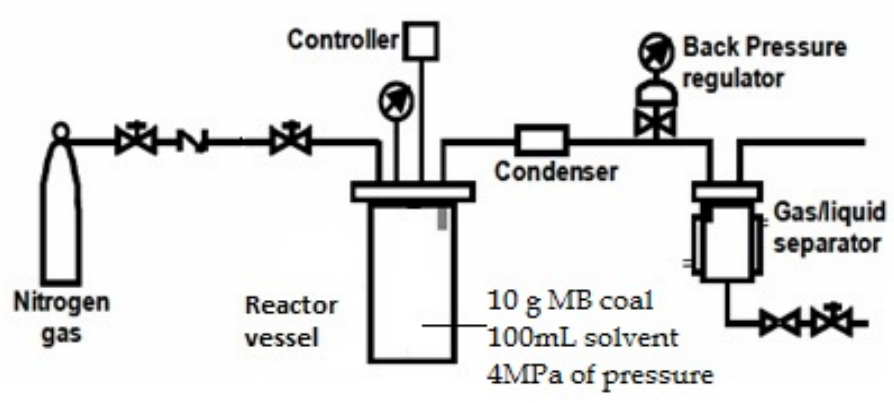

Figure 1: Schematic diagram of reactor system. 
The temperature and pressure used were $380-400^{\circ} \mathrm{C}$ and at $4 \mathrm{MPa}$, respectively. Liquefaction experiment started with leak-check test, followed by introducing nitrogen into the system and heated to desired temperature. After certain reaction time at desired condition, the reactor vessel was rapidly cooled to room temperature in an ice bath. The reactor vessel was depressurised to ambient pressure, and the coal extract was washed with tetrahydrofuran (THF) and filtered to obtain coal liquefaction residue (CLR) and crude tar. The crude tar was then separated into oil (hexane-soluble), asphaltene (toluene-soluble) and preasphaltene (THF soluble) by sequential Soxhlet extraction method. Coal liquefaction residue collected after filtration of coal extracts was dried overnight in vacuum oven at $100^{\circ} \mathrm{C}$. The mass of oil+gas products were calculated by subtracting the total mass of asphaltene, pre asphaltene and residue from mass of original coal being subjected to liquefaction. The contribution from the gas is considered minimal, since the reaction was carried out at temperature of less than $450^{\circ} \mathrm{C}$.

\section{Results and discussion}

\subsection{Process aspects of coal liquefaction and derivatives}

Generally, coal liquefaction considered important due to petroleum decline reserves as this process can convert coal to vehicle fuels such as diesel and gasoline. Coal can be converted into liquid fuels by indirect liquefaction process through catalytic conversion of syngas from gasification into clean hydrocarbons and oxygenated transportation fuels. Coal also can be liquefied directly through direct liquefaction to obtain liquid fuels at temperature around $400-450^{\circ} \mathrm{C}$ under nitrogen or hydrogen pressure in a suitable solvent [7]. In this study, coal is being liquefied through direct liquefaction process as the temperature used is below $450^{\circ} \mathrm{C}$ in a batchwise reactor system.

In coal liquefaction process, coal slurry is prepared by mixing pulverized coal with solvent. The mixture then subjected to reactor in which hydrogen or nitrogen pressure being introduced. As slurry being heated until the whole process completed, reaction mechanism occurs. Reaction mechanism of coal liquefaction consists of three steps [12]. In the first step, smaller molecules within the structure in coal slurry is extracted by heated solvent, releasing some gases and water. Free radicals forming due to breaking of some weaker bonds then stabilized by hydrogen atoms from donor solvents and/or hydrogen gas. In the second step, a rapid chain reaction occurs in which covalent bonds of coal structure being attacked by the radicals causing formation of some asphaltenes. In the third step, more liquids and gases are formed as hydrogenation of asphaltene takes place. In coal liquefaction process, the second step should be controlled to avoid integration of radicals, while the third step should be accelerated to increase coal conversion and the oil yield. 


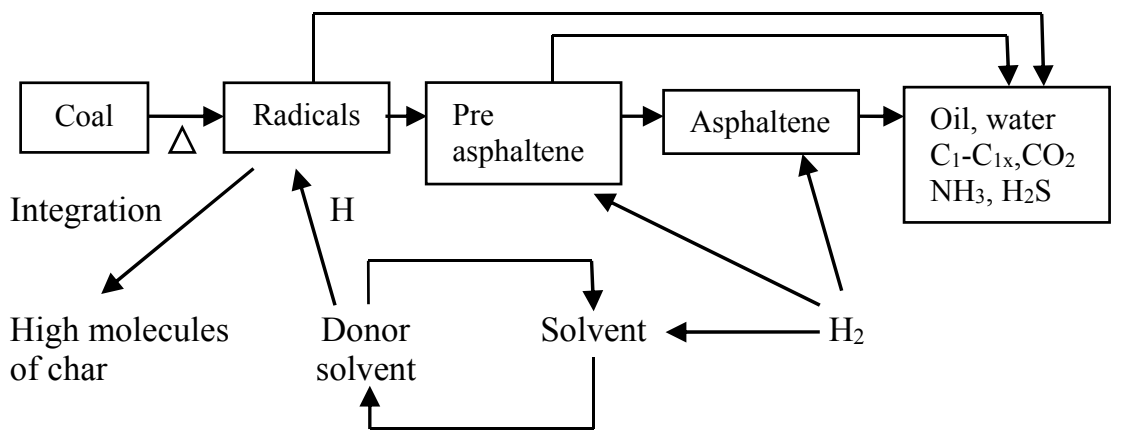

Figure 2: Reaction mechanism of coal liquefaction [12].

\subsection{Effect of temperature and reaction time on conversion and product yield}

Coal liquefaction using tetralin-glycerol solvent system with ratio of 70:30 (v/v) at different temperature and reaction time was successfully carried out in a batchwise reactor system. Temperatures at $380^{\circ} \mathrm{C}$ and $400^{\circ} \mathrm{C}$ were chosen because they were within the range where mild thermal cracking of cross-linked polymerized coal structure occurred leading to formation of extractable pyrolysis products that dissolve in the near- or supercritical solvent. It is also known that coal begin to soften at around $375^{\circ} \mathrm{C}$ [13], implying temperature used in this study is in the region where softening of coal has occurred.

Table 2 summarizes liquefaction properties of Mukah Balingian coal at different temperature and reaction time. It can be observed from Table 2 that for temperature of $380^{\circ} \mathrm{C}, 66.75 \%$ of conversion is observed in a 15 min reaction. As the reaction time was increased to $30 \mathrm{~min}, 71.12 \%$ conversion and $39.21 \%$ oil + gas yield were achieved. When the reaction time increased to $45 \mathrm{~min}$, conversion is slightly increased by $2 \%$ with increasing oil+gas yield and asphaltene while decreasing pre-asphaltene yield. On the basis of these results, it is apparent that conversion of coal to THF soluble is relatively fast. Huang and Schobert [14] also observed the similar trend in their study in liquefaction of low rank coals. In their study, fairly high conversion was found to be obtained within $10 \mathrm{~min}$. Similarly to this present study, conversion of asphaltenes or pre-asphaltene to oil+gas are found to be slower and appear to require longer reaction time which explains the trend in as oil+gas yield increased as reaction time being increased.

Temperature of $400^{\circ} \mathrm{C}$ seems to have similar trend for liquefaction results as that of $380^{\circ} \mathrm{C}$. With an increase in temperature, the conversion also increase as $75.37 \%$ of the coal converted in a 15 min reaction time. Additional reaction time was found to increase conversion, yet there is almost no significant effect between the one with $30 \mathrm{~min}$ and $45 \mathrm{~min}$ reaction time, in which percentage of converted coal to THF-solubles are $78.05 \%$ and $78.55 \%$, respectively. Additionally, it was also found that at this temperature, percentages of oil+gas yield obtained were almost similar despite an increasing reaction time being applied to the process. 
Asphaltene and pre-asphaltene were found to be produced at higher amount too. A review by Banga and Varshney [15] on glycerol has stated that applying heat to glycerol can degrade the compound, forming diols or acids byproducts which can catalyze polymerization. In this study, byproducts obtained upon glycerol heating favours polymerization thus promotes formation of higher molecular weight asphaltene and pre-asphaltene instead of lower molecular weight oil+gas product. As compared to $380^{\circ} \mathrm{C}$, polymerization at $400^{\circ} \mathrm{C}$ is at higher rate as high temperature supplied causing number of free radicals formed at high speed. On one hand, hydrogen from tetralin will cap the free radicals to form low molecular weight compound. The glycerol byproducts on the other hand favours polymerization. It was suspected that these diols or acids causing recombination within the compounds and causing an increment in percentage of asphaltene and pre-asphaltene. With prolonged reaction time, this allows more time for recombination reaction to occur, thus lowering lower molecular weight percent yield.

Table 2: Liquefaction properties of Mukah Balingian coal at different temperature and reaction time.

\begin{tabular}{|c|c|c|c|c|c|}
\hline \multirow{2}{*}{$\begin{array}{c}\text { Temp. } \\
\left({ }^{\circ} \mathrm{C}\right)\end{array}$} & \multirow{2}{*}{$\begin{array}{c}\text { Reaction } \\
\text { time } \\
\end{array}$} & \multirow{2}{*}{$\begin{array}{c}\text { Conv. } \\
(\%)\end{array}$} & \multicolumn{3}{|c|}{ Products yield (\%) } \\
\cline { 4 - 6 } & & & Oil+gas & Asp. & Pre-Asp. \\
\hline 380 & 15 & 66.75 & 35.23 & 7.68 & 23.84 \\
& 30 & 71.12 & 37.21 & 15.87 & 18.04 \\
& 45 & 73.21 & 39.73 & 15.75 & 17.73 \\
\hline 400 & 15 & 75.37 & 38.24 & 9.61 & 27.52 \\
& 30 & 78.05 & 39.84 & 17.08 & 21.13 \\
& 45 & 78.55 & 37.02 & 20.61 & 20.92 \\
\hline
\end{tabular}

* Liquefaction conditions : $70: 30(\% \mathrm{v} / \mathrm{v})$ tetralin-glycerol solvent system, $4 \mathrm{MPa} \mathrm{N}_{2}$ pressure, coalto-solvent ratio $=1: 10$.

Based on these results obtained, it was clearly found that at lower liquefaction temperature of $380^{\circ} \mathrm{C}$, retrogressive reactions in this co-solvent system are negligible. It was suspected that direct route of mechanism in coal liquefaction occurs at this temperature in which coal constituents being extracted and mild thermal cracking of cross-link polymerized coal structure takes place [13].

$$
\text { Coal } \rightarrow \text { Pre-asphaltene } \rightarrow \text { Asphaltene } \rightarrow \text { Oil+gas }
$$

Due to this, formation of pre-asphaltene and asphaltene found to decrease while oil+gas yield increased as an increment in reaction time being applied.

With the liquefaction temperature increased to $400^{\circ} \mathrm{C}$, retrogressive reaction began to take place markedly. At this temperature, higher production of free radicals due to endothermic reaction of pyrolysis occurs and they cannot be stabilized by hydrogenation in time due to limited hydrogen donating ability of 
this co-solvent system. As a result, they regressively recombine to form polymeric products. Table 2 shows that for liquefaction at $400^{\circ} \mathrm{C}$, regressive transformation of oil + gas $\longrightarrow$ asphaltene might have occurred. In addition, the by-products from glycerol heating which catalyzes polymerization also contributes to this unfavourable transformation. This explains the reason why as reaction time being increased, this regressive transformation becomes predominant at this liquefaction temperature.

\section{Conclusion}

This study reveals the characteristics of tetralin-glycerol co-solvent system in coal liquefaction process by studying the effects of temperature and reaction time on conversion and percent of products yield. Generally, this solvent system was found to be temperature sensitive as different temperature used caused different trend in percent of products yield obtained as reaction time being increased. Although coal conversion was found to increase as temperature increased, glycerol degradation upon heating had asked for careful consideration for temperature usage in liquefaction process with this type of co-solvent system.

\section{Acknowledgements}

The authors would like to thank Ministry of Higher Learning Education Malaysia for funding the research (Grant No.: 600-RMI/FRGS 5/3 (21/2012)) and Universiti Teknologi MARA.

\section{References}

[1] Whiteburst, D.D., Mitchell, T.O. and Farcasiu, M. "Coal liquefaction: The chemistry and technology of thermal process", Academic Press, New Jersey, 1980.

[2] Redlich , P.J., Hulston, C.K.J., Sasaki, M., Jackson, W.R., Larkins, F.P. and Marchall, M. (1996). Comparison of coal liquefaction yields from two different reactor systems. Fuel, 75, 1467-1470.

[3] Hu, H., Sha, G. and Chen, G. (2000). Effect of solvent swelling on liquefaction of Xinglong coal at less severe condition. Fuel Processing Technology, 68, 33-43.

[4] Şimşek, E.H., Karaduman, A. and Olcay, A. (2001). Liquefaction of Turkish coals in tetralin with microwaves. Fuel Processing Technology, 73, 111-125.

[5] Sangon, S., Ratanavaraha, S., Ngamprasertsih, S. and Prasassarakich, P. (2006). Coal liquefaction using supercritical toluene-tetralin mixture in a semi-continuous reactor. Fuel Processing Technology, 87, 201-207.

[6] Li, H., Hu, H., Jin, L., Hu, S. and Wu, B. (2008). Approach for promoting liquid yield in direct liquefaction of Shenhua coal, Fuel Processing Technology, 89, 1090-1095.

[7] Shui, H., Cai, Z. and Xu, C. (2010). Recent advances in direct coal liquefaction. Energies, 3, 155-170.

[8] Ishak, M.A.M., Ismail, K., Abdullah, M.F., Kadir, M.O.A., and Mohamed, A.R., (2005). Liquefaction of Malaysian coal via High-Pressure High-Temperature BatchWise Reactor System, Coal Preparation Journal, Vol 25, 221-237. 
[9] Karaca, S., Ceylan, K. and Olcay, K. (2001). Catalytic dissolution of two Turkish lignites in tetralin under nitrogen atmosphere: effects of the extraction parameters on the conversion. Fuel, 80(4), 559-564.

[10] Ghani, Z.A., Ishak M.A.M and Ismail, K. (2011). Direct liquefaction of Mukah Balingian low-rank Malaysian coal: optimization using response surface methodology (RSM). Asia-Pacific Journal of Chemical Engineering, Vol 3, Issue 2, 481-487.

[11] Ali, S.N., Yusop, M.F., Ismail, K., Ghani, Z.A., Ishak, M.A.M. and Mohamed, A.R. (2014). Tetralin-Glycerol as Solvent in Direct Liquefaction of Mukah Balingian Coal. Energy Procedia, Volume 52, 618-625.

[12] Shi, S., Li, W., Wang, Y., Guo, Z. and Li, K. (2008). Study on mechanism of coal liquefaction reaction and a new process concept. Journal of Coal Science \& Engineering (China), 14(1), 119-124.

[13] Wilhelm, A. and Hedden, K. (1986). A non-isothermal experimental technique to study coal extraction with solvents in liquid and supercritical state. Fuel 65(9), 1209-1215.

[14] Huang, L. and Schobert, H. (2005). Comparison of temperature conditions in direct liquefaction of selected low-rank coals. Energy \& Fuels, 19, 200-207.

[15] Banga, S. and Varshney, P.K. (2010). Effect of impurities on performance on biodiesel: A review. Journal of Scientific \& Industrial Research, Vol. 69, pp. 575-579. 